\title{
Efficacy of sorafenib therapy in patients with advanced hepatocellular carcinoma in Indian population
}

\author{
Alit Abraham ${ }^{1}$, Charumathi Purushothaman ${ }^{1}$, Dhanya Damien ${ }^{1}$, Jackson James ${ }^{1}$, \\ Prudence Attilade Rodrigues ${ }^{1}$, Gursharan Singh ${ }^{2}$
}

${ }^{1}$ Department of Pharmacy Practice, P.S.G College of Pharmacy, Coimbatore 641004, Tamil Nadu, India.

${ }^{2}$ Department of Hepatobiliary and Liver Transplantation Surgery, P.S.G Hospitals, Coimbatore 641004, Tamil Nadu, India.

\begin{abstract}
Aim: Hepatocellular carcinoma (HCC) is the fourth most common type of cancer and the third leading cause of cancer-related mortality. Sorafenib is an oral multikinase inhibitor that is used for unresectable advanced HCC. It is only approved systemic therapy for advanced HCC. Methods: A retrospective prospective study conducted in a multispeciality hospital with 50 patients who received sorafenib. The primary outcome of the study was to find out the survival rate of patients treated with sorafenib. The secondary outcome of the study was to explore the efficacy and safety of sorafenib in a progression of HCC. Results: The median overall survival in the Indian population was found as 114 days (3.8 months) after sorafenib therapy. The efficacy of the drug sorafenib was assessed by the survival days which were based on the changes in laboratory values such as haematological and clinical biochemistry. The adverse drug reaction documented in this study was vomiting, abdominal pain; fatigue; anorexia; hyperbilirubinemia; diarrhoea; hand-foot syndrome; rash; rectal bleeding; insomnia; constipation; thrombocytopenia and abdominal discomfort. Conclusion: Sorafenib improves the overall survival of the patients with advanced HCC in Indian population up to 3.8 months. It is a safe and effective treatment for patients with advanced HCC in Indian population. The survival of patients was found to be depended on the liver function.
\end{abstract}

Key words: Hepatocellular carcinoma; sorafenib; Indian population

\section{Corresponding Author:}

Dr. Alit Abraham, Department of Pharmacy Practice, P.S.G College of Pharmacy, Coimbatore 641004, Tamil Nadu, India.

E-mail: alit.abraham@gmail.com

Received: 17-02-2016; Accepted: 20-07-2016

\section{INTRODUCTION}

Hepatocellular carcinoma (HCC) is the fourth most common type of cancer and the third leading cause of cancer-related mortality. ${ }^{[1]}$ Approximately $4 \%$ of new cases diagnosed worldwide. About 782,000 new cases are diagnosed in 2012. In India, the age-adjusted incidence rate of HCC for men ranges from 0.7-7.5 and for women 0.2-2.2 per 100,000 of population per year. The male: female ratio for HCC in India is 4:1. The age-standardized mortality rate for HCC in India for men is $6.8 / 100,000$ and for women is $5.1 / 100,000$. The incidence of HCC is increasing in India. India is one of the developing countries among the worldwide and the incidence of HCC is being increased in

\begin{tabular}{|l|c|}
\hline \multicolumn{2}{|c|}{ Access this article online } \\
\hline \multirow{2}{*}{ Website: } & Quick Response Code \\
http://www.hrjournal.net/ & \\
\hline DOI: &
\end{tabular}

the current decades. ${ }^{[2]}$ The main cause of HCC is cirrhosis, hepatitis B virus infection, chronic hepatitis C virus infection, and alcohol abuse and aflatoxin exposure. Other risk factors include non-alcoholic steatohepatitis, alcohol abuse, obesity, fatty liver, hemochromatosis, Wilson's disease; type 2 diabetes mellitus, haemophilia alpha 1 antitrypsin deficiency, autoimmune hepatitis, smoking and tobacco, and diabetes. ${ }^{[3]}$ Advanced HCC is the multinodular/ unresectable HCC, HCC with extrahepatic spread or HCC with vascular invasion. ${ }^{[4]}$

The treatment options for HCC include surgical resection, liver transplantation, transarterial chemoembolization or

This is an open access article distributed under the terms of the Creative Commons Attribution-NonCommercial-ShareAlike 3.0 License, which allows others to remix, tweak, and build upon the worknon-commercially, as long as the author is credited and the new creations are licensed under the identical terms.

For reprints contact: service@oaepublish.com

How to cite this article: Abraham A, Purushothaman C, Damien D, James J, Rodrigues PA, Singh G. Efficacy of sorafenib therapy in patients with advanced hepatocellular carcinoma in Indian population. Hepatoma Res 2016;2:224-8. 
Table 1: Baseline characteristics along with log rank significance

\begin{tabular}{|c|c|c|c|c|}
\hline Baseline characters & Patients $n(\%)$ & Median overall surveillance & $95 \% \mathrm{Cl}$ & $P$ value \\
\hline \multicolumn{5}{|l|}{ Age } \\
\hline$>63$ years & $19(46.3 \%)$ & 114 & $82-67$ & \multirow[t]{2}{*}{0.708} \\
\hline$<63$ years & 22 (53.7\%) & 108 & $100-290$ & \\
\hline \multicolumn{5}{|l|}{ Gender } \\
\hline Male & 33 (80.5\%) & 117 & $41-116$ & \multirow[t]{2}{*}{0.673} \\
\hline Female & $8(19.5 \%)$ & 108 & $31-77$ & \\
\hline \multicolumn{5}{|l|}{ Alcohol } \\
\hline Alcoholic & $9(22 \%)$ & 125 & $92-59$ & \multirow[t]{2}{*}{0.086} \\
\hline Non alcoholic & 32 (78\%) & 108 & 95-205 & \\
\hline \multicolumn{5}{|l|}{ Smoking } \\
\hline Smoker & $6(14.6 \%)$ & 61 & $10-467$ & \multirow[t]{2}{*}{0.947} \\
\hline Non smoker & 35 (85.4\%) & 117 & $128-248$ & \\
\hline \multicolumn{5}{|l|}{ Child-Pugh class } \\
\hline $\mathrm{B}$ & $23(56.1 \%)$ & 125 & 147-362 & \multirow[t]{2}{*}{0.013} \\
\hline $\mathrm{C}$ & $18(43.9 \%)$ & 66 & $122-252$ & \\
\hline \multicolumn{5}{|l|}{ PVT } \\
\hline Present & 19 (46.3\%) & 117 & $93-267$ & \multirow[t]{2}{*}{0.982} \\
\hline Absent & $22(53.7 \%)$ & 108 & $91-289$ & \\
\hline \multicolumn{5}{|l|}{ Reason } \\
\hline Hepatitis & $13(31.7 \%)$ & 71 & $31-111$ & \multirow[t]{2}{*}{0.146} \\
\hline Others & 28 (68.3\%) & 121 & $83-157$ & \\
\hline
\end{tabular}

Cl: confidence interval; PVT: portal vein thrombosis

Table 2: Adverse drug reaction

\begin{tabular}{lc}
\hline Adverse drug reaction & Number of patients \\
\hline Anorexia & 10 \\
Abdominal pain & 16 \\
Vomiting & 19 \\
Insomnia & 3 \\
Hyperbilurubinimia & 10 \\
Diarrhoea & 9 \\
Thrombocytopenia & 2 \\
Rectal bleding & 4 \\
Fatigue & 16 \\
Hand foot syndrome & 6 \\
Constipation & 2 \\
Rash & 6 \\
Abdominal discomfort & 1 \\
Aniemia & 1 \\
Weight loss & 1 \\
Alopecia & 1 \\
Body pain & 2 \\
\hline
\end{tabular}

radioembolization, radiofrequency ablation, and sorafenib..$^{[5]}$

Sorafenib is an oral multikinase inhibitor that is used for unresectable advanced HCC. It is only approved systemic therapy for advanced HCC. ${ }^{[6]}$ It affords a modest gain in survival by delaying the progression of HCC and improves the survival of the patient up to 3 to 6 months.

Sorafenib inhibits tumour cell proliferation and tumour angiogenesis and increases the rate of tumour apoptosis. It is made by inhibiting the tyrosine protein kinases (vascular endothelial growth factor receptor 1, 2, 3 and platelet-derived growth factor receptor $\beta$ ). And it also inhibits some intracellular serine/ threonine kinases Raf kinases (Raf 1 and more actively C-Raf than B-Raf). ${ }^{[7]}$

But how long a person will survive after the sorafenib therapy in the Indian population has not been established. Since sorafenib is a costlier therapy, whether the treatment with sorafenib therapy is safe and effective among the Indian population with advanced HCC has not been demonstrated.

\section{METHODS}

\section{Patients}

This retrospective-prospective observational study was conducted in the Department of Gastroenterology at the multispecialty teaching hospital of P.S.G Medical Science and Research Institute, Coimbatore. Fifty patients who had received sorafenib from January 2009 to December 2014 were collected from the hospital database.

Patient selection was based on patients treated with sorafenib; patients with advanced HCC; and the patient with cirrhosis, hepatitis B and C, steatohepatitis and alcoholic liver disease. Demographic details, disease condition, treatments and adverse drug reaction (ADR) were collected from the hospital database and the Medical Record Department. Survival rate was collected by the phone call. The laboratory investigations such as hematology, serology, microbiology, radiology, computed tomography scan, ultrasound-guided, cytology, urology, biochemistry details of the patients were gathered. Out of 50 patients, 41 patients were recruited for the study.

\section{Treatment}

Usually, sorafenib was given as $400 \mathrm{mg}$ bid. ${ }^{[8]}$ In our patient population mainly three types of dosing regimen were used. They are $400 \mathrm{mg}$ bd, $600 \mathrm{mg}$ daily, and $200 \mathrm{mg}$ bid with good compliance. Dose reduction and treatment regimen were based on the recommendations. 

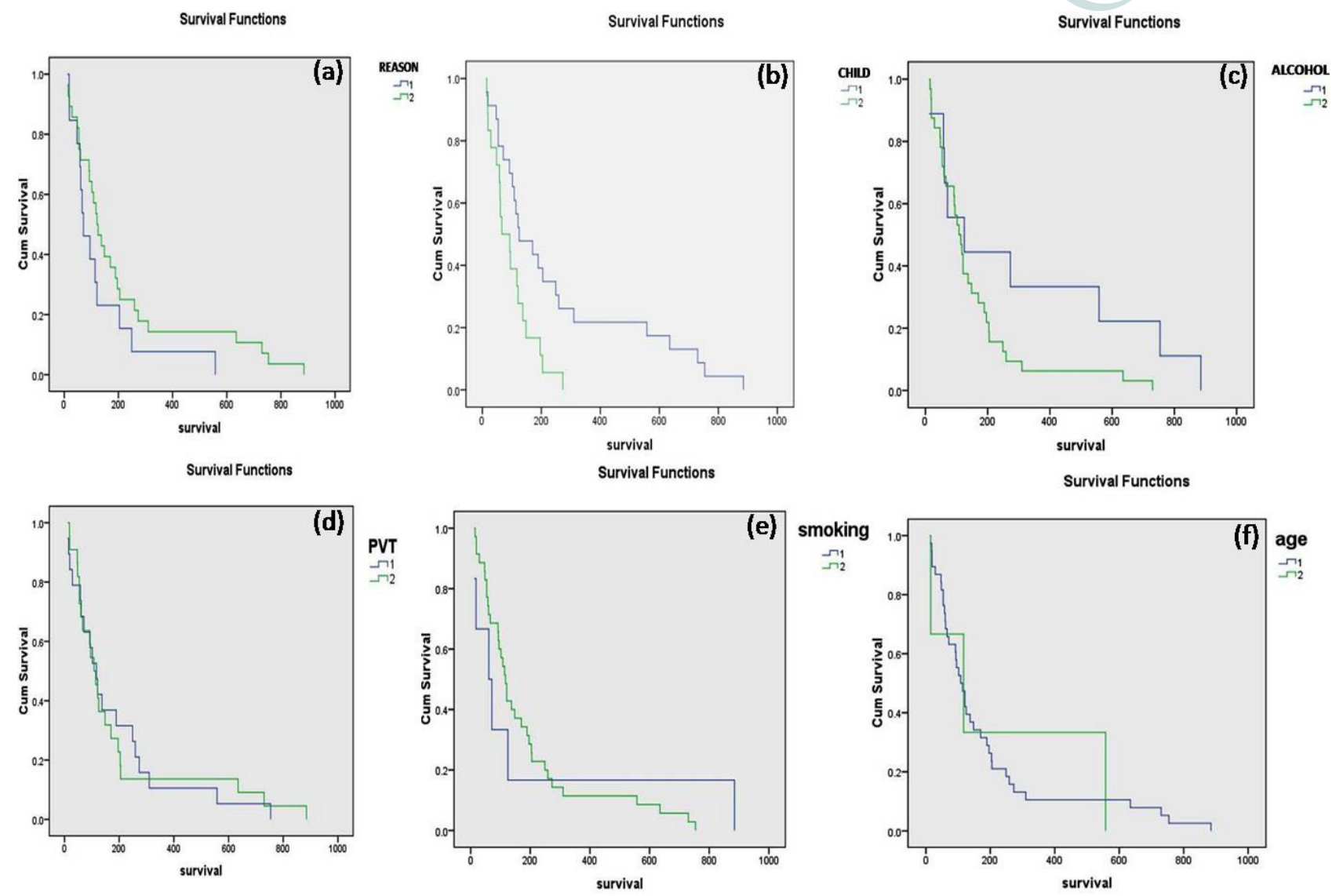

Survival Functions

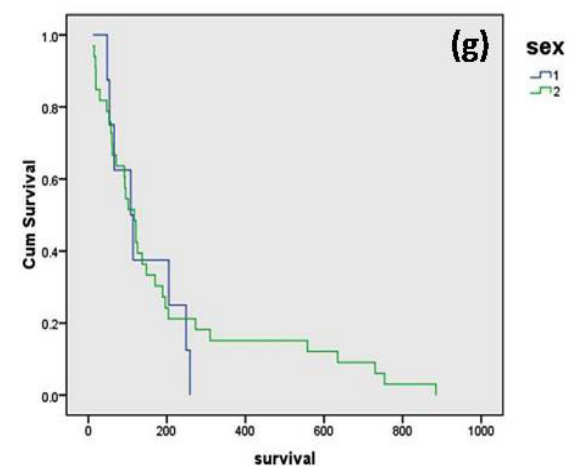

Figure 1: Kaplan-Meier curve. (a) Curve for reasons (1: hepatits; 2: others); (b) curve for Child-Pugh class (1: class B; 2: class C); (c) curve for alcohol (1: alcoholic; 2 : non alcoholic); (d) curve for PVT (1: present; 2: absent); (e) curve for smoking (1: smokers; 2: non smokers); (f) curve for age (1: > 63 years; 2 : < 63 years); (g) curve for gender (1: female; 2 : male). PVT: portal vein thrombosis

At the end of the study, 7 patients were alive and 34 patients died. The survival days were calculated till April 2015.

\section{Efficacy}

The efficacy of the drug was based on the changes in laboratory investigations such as haematological parameters like haemoglobin, platelets, white blood cell (WBC) level as after the therapy and liver function parameters like serum bilirubin, aspartate transaminase (AST), alanine transaminase (ALT), alkaline phosphatase (ALP) and serum albumin levels which was monitored after the therapy. Adverse drug reactions were collected from the case files.

\section{Statistical analysis}

The primary outcome was the overall mean survival which was calculated for all the patients using KaplanMeier method. ${ }^{[9]}$ All the statistical analysis was done in SPSS software version 16.00. The log-rank analysis was used to determine the significance at the confidence interval was $95 \%$.

\section{RESULTS}

\section{Patient's characteristics}

A total of 50 patients were found to be treated with sorafenib in our hospital between January 2009 and December 2014. In that, 1 was found to be taken up renal cell carcinoma, 
so he/she was excluded from the study, we were unable to contact either 8 since no contact details were available, the rest of 41 patients were included in the study. They were followed up for about 4 months that is January 2015 to April 2015. Median overall survival was 3.8 months, ranging from 12 to 885 days. The baseline characteristics and median overall surveillance are listed in Table 1.

For some patients physicians done ablative therapies like transarterial chemoembolization (TACE) and radiofrequency ablation (RFA) were done, the details regarding that were like as follows, for around 3 patients RFA was done, around 4 were undergone for TACE, for around 2 patients were done with both TACE and RFA. For the rest of their details was not available. Usually, sorafenib was given as $400 \mathrm{mg}$ bid. In our patient population mainly 3 types of dosing regimen were used. They are $400 \mathrm{mg}$ bd, $600 \mathrm{mg}$ daily, and $200 \mathrm{mg}$ bid. They were given to the patients in the following manner 30 (73.17\%), 1 (2.44\%), and 10 (24.39\%) respectively. Among this population due to the ADR, dose reduction was done in 3 patients from $400 \mathrm{mg}$ bid to $200 \mathrm{mg}$ bd, and 2 was ceased and continued. Apart from this, all the patients showed good compliance with the therapy.

\section{Treatment outcome}

The overall survival in our population was estimated using the Kaplan-Meier method using statistical software SPSS 16.0 for Windows. The overall survival was found as 114 days. The Kaplan-Meier curve for each criterion was illustrated in Figure 1.

The efficacy of the drug sorafenib was assessed by the changes in laboratory values such as haematological and clinical biochemistry. The haemoglobin level was found to be increased in $34(82.9 \%)$ patients and no changes were observed in 7 (17.1\%) patients. The platelet count was found to be raised in $30(73.2 \%)$ patients and no observed changes were found in $11(26.8 \%)$ patients. The WBC count was found to be decreased in $30(73.2 \%)$ and no observed change was found in $11(26.8 \%)$ patients. While looking to clinical liver parameters the bilirubin level was reduced for 19 (46.3\%) patients and increased in $22(53.7 \%)$ patients. That may be due to adverse reaction to the drug (hyperbilirubinemia). The albumin level was found to be increased in 26 (63.4\%) patients and no observed changes were found in 15 (36.6\%). The AST level was found to be decreased in $32(78 \%)$ patients and no observed changes were found in $9(22 \%)$ patients. The ALP level was found to be decreased in $32(78 \%)$ patients and no observed changes were found in $9(22 \%)$ patients. The ALT level was found to be reduced in 33 (80.5\%) patients and no observed changes were found in 8 (19.5\%) patients. Therefore the efficacy of the drug sorafenib has been proved from the favourable changes in the laboratory values of the patients. ADRs found was illustrated in Table 2.

\section{DISCUSSION}

In Indian population, therapy with sorafenib was indicated in patients with HCC of Barcelona Clinic Liver Cancer (BCLC) stage $\mathrm{C}$. The combination of sorafenib with transplantation or resection, either sequential or concomitant, cannot be recommended outside clinical trials; however, sorafenib can be given for residual/recurrent disease after surgery/ transplant/TACE/RFA. ${ }^{[2]}$

Køstner et al..$^{[10]}$ conducted a retrospective study with 76 patients in 2011 in Denmark found that patients in performance status 0 - 1 had a median overall survival of 6.2 months compared to 1.8 months in patients with poorer performance status. Child-Pugh A patients had median overall survival of 6.6 months versus 3.6 months among patients with Child-Pugh B or C.

In this study, we found that the efficacy was depending upon the survival rate which has depended on upon the liver functions which can be determined through liver function test and haematological parameters.

Ji et al. ${ }^{[1]}$ conducted an open-label randomized study with 189 patients with advanced HCC Child-Pugh B or C HCC patients into 2 groups, one with sorafenib and other with best supportive care. Median overall survival was 4 months and 3.5 months in the sorafenib group and best supportive care group respectively. In the sorafenib group, the median performance status and overall survival were significantly longer in patients with BCLC stage B and Child-Pugh class B liver function.

In this study, Child-Pugh B has more median overall survival when compared to Child-Pugh C, 125 days and 66 days respectively. The overall median survival was shown to be similar to the above study that was 3.8 months.

Llovet et al. ${ }^{[12]}$ conducted randomized double-blind placebo-controlled phase 3 trial at 121 centres in 21 countries in Europe, North America, South America, and Australia in 602 patients. The study shows that the median overall survival was 10.7 months in sorafenib group and 7.9 months in the placebo group. The median time to radiological progression was 5.5 months in sorafenib group and 2.8 months in the placebo group.

In this study about 8 patients had good survival (558 days to 885 days, in which sorafenib was highly effective.

Køstner et al..$^{[10]}$ conducted a retrospective study in 2011 in Denmark with 76 patients in that they found that fatigue (68\%) was the main ADR followed by anorexia (47\%); diarrhoea (42\%); rash (33\%); nausea (32\%); and hand-foot syndrome (28\%). Sorafenib is generally tolerable also in more compromised patients as the number and grade of adverse events did not differ significantly between the patients with good versus poor performance status and liver function.

In this study, main ADRs were fatigue, anorexia, diarrhoea, rash, nausea, hand-foot syndrome. Dose reduction was made 
to 2 patients in order to overcome the ADR. One patient ceased and continued therapy. Further recommendations were made to overcome the ADR but we have not included that recommendation in our study.

Llovet et al. ${ }^{[12]}$ conducted the sorafenib Hepatocellular Carcinoma Assessment Randomized Protocol study shows that the adverse event is more common in sorafenib group compared to the placebo group, were diarrhoea $(n=39)$, fatigue $(n=22)$, hand-foot syndrome (HFS) $(n=21)$. Sorafenib associated adverse event led to dose reductions and interruptions in a subgroup of patients. The study enrolled 602 patients; this was phase 3 double blind placebo controlled trial.

Expect from the usual adverse drug reactions sorafenib was found as a good choice for treating patients with advanced HCC.

Limitations, all the data were collected retrospectively except survival rate, no computed tomography scan details available so that it was unable to assess the tumour size, less population was involved there were only 41 samples were available, no proper contact details of the patients were available because of that some patients survival days were excluded, lack of follow-up of some patients after treatment.

In conclusion, sorafenib improves the overall survival of the patients with advanced HCC in Indian population. The median overall survival was found to be 114 days (3.8 months). It is a safe and effective treatment for patients with advanced HCC in Indian population. The survival of patients was found to depend on the liver function. The adverse effect was found to be almost same as other countries apart from that we found insomnia in our population. The adverse effects include fatigue, diarrhoea, HFS, hyperbilirubinemia, nausea and vomiting. Finally, we conclude that sorafenib is best oral systemic therapy for advanced HCC in Indian population.

\section{Financial support and sponsorship}

Nil.

\section{Conflicts of interest}

There are no conflicts of interest.

\section{REFERENCES}

1. Zhang T, Ding X, Wei D, Cheng P, Su X, Liu H, Wang D, Gao H. Sorafenib improves the survival of patients with advanced hepatocellular carcinoma: a meta-analysis of randomized trials. Anticancer Drugs 2010;21:326-32.

2. Kumar A, Acharya SK, Singh SP, Saraswat VA, Arora A, Duseja A, Goenka MK, Jain D, Kar P, Kumar M, Kumaran V, Mohandas KM, Panda D, Paul SB, Ramachandran J, Ramesh H, Rao PN, Shah SR, Sharma H, Thandassery RB; The INASL Task-Force on Hepatocellular Carcinoma. The Indian National Association for Study of the Liver (INASL) Consensus on Prevention, Diagnosis and Management of Hepatocellular Carcinoma in India: The Puri Recommendations. J Clin Exp Hepatol 2014;4:S3-26.

3. Davis GL, Dempster J, Meler JD, Orr DW, Walberg MW, Brown B, Berger BD, O’Connor JK, Goldstein RM. Hepatocellular carcinoma: management of an increasingly common problem. Proc (Bayl Univ Med Cent) 2008;21:266-80.

4. Hu H, Duan Z, Long X, Hertzanu Y, Shi H, Liu S, Yang Z. Sorafenib combined with transarterial chemoembolization versus transarterial chemoembolization alone for advanced-stage hepatocellular carcinoma: a propensity score matching study. PLoS One 2014;9:e96620.

5. Nakano M, Tanaka M, Kuromatsu R, Nagamatsu H, Sakata K, Matsugaki S, Kajiwara M, Fukuizumi K, Tajiri N, Matsukuma N, Sakai T, Ono N, Yano Y, Koga H, Kurogi J, Takata A, Sumie S, Satani M, Yamada S, Niizeki T, Aino H, Iwamoto H, Torimura T, Sata M. Efficacy, safety, and survival factors for sorafenib treatment in Japanese patients with advanced hepatocellular carcinoma. Oncology 2013;84:108-14.

6. Xie B, Wang DH, Spechler SJ. Sorafenib for the treatment of hepatocellular carcinoma: a systematic review. Dig Dis Sci 2012;57:1122-9.

7. Peixoto RD, Renouf DJ, Gill S, Cheung WY, Lim HJ. Relationship of ethinity and overall survival in patients treated with sorafenib for advanced hepatocellular carcinoma. $J$ Gastrointest Oncol 2014;5:259-64.

8. Zheng SZ, Liu DJ, Sun P, Yu GS, Xu YT, Gong W, Liu J. Feasibility and safety of sorafenib treatment in hepatocellular carcinoma patients with spontaneous rupture. World J Gastroenterol 2014;20:16275-81.

9. Abdel-Rahman O, Abdelwahab M, Shaker M, Abdelwahab S, Elbassiony M, Ellithy M. Sorafenib for Egyptian patients with advanced hepatocellular carcinoma; single centre experience. $J$ Egypt Natl Canc Inst 2014;26:9-13.

10. Køstner AH, Sorensen M, Olesen RK, Grønbæk H, Lassen U, Ladekarl M. Sorafenib in advanced hepatocellular carcinoma: a nationwide retrospective study of efficacy and tolerability. Scientific World Journal 2013;2013:931- 72.

11. Ji YX, Zhang ZF, Lan KT, Nie KK, Geng CX, Liu SC, Zhang L, Zhuang XJ, Zou X, Sun L, Zhang ZC. Sorafenib in liver function impaired advanced hepatocellular carcinoma. Chin Med Sci J 2014;29:7-14.

12. Llovet JM, Ricci S, Mazzaferro V, Hilgard P, Gane E, Blanc JF, de Oliveira AC, Santoro A, Raoul JL, Forner A, Schwartz M, Porta C, Zeuzem S, Bolondi L, Greten TF, Galle PR, Seitz JF, Borbath I, Häussinger D, Giannaris T, Shan M, Moscovici M, Voliotis D, Bruix J; SHARP Investigators Study Group. Sorafenib in advanced hepatocellular carcinoma. N Engl J Med 2008;359:378-90. 